Pol. J. Food Nutr. Sci., 2012, Vol. 62, No. 3, pp. 143-150

DOI: $10.2478 / \mathrm{v} 10222-011-0045-1$ http://journal.pan.olsztyn.pl

Original Paper

Section: Food Technology

\title{
Freeze-Drying Preservation of Yeast Adjunct Cultures for Cheese Production
}

\author{
Xymena Potomska ${ }^{1 *}$, Maria Wojtatowicz ${ }^{1}$, Barbara Zarowska ${ }^{1}$, Marek Szottysik ${ }^{2}$, Józefa Chrzanowska ${ }^{2}$ \\ ${ }^{1}$ Department of Biotechnology and Food Microbiology, Wroclaw University of Environmental \\ and Life Sciences, ul. Chetmonskiego 37/41, 51-630 Wroclaw, Poland \\ ${ }^{2}$ Departament of Animal Products Technology and Quality Management, Wroclaw University \\ of Environmental and Life Sciences, ul. Chetmońskiego 37/41, 51-630 Wroclaw, Poland
}

Key words: Yarrowia lipolytica, Candida famata, Candida kefyr, Candida sphaerica, freeze-dried cheese starter cultures, cell viability and growth activity

Four yeast strains: Yarrowia lipolytica PII6a, Candida famata MI1a, C. kefyr PII1b, C. sphaerica FII7a, adjunct cultures for cheese production were preserved by freeze-drying. The effect of process parameters and cryoprotective agents on cell survival and stability of growth characteristics was evaluated. Among three lyophilisation protocols, the process with three-step drying at temperatures of $-38^{\circ} \mathrm{C},-20^{\circ} \mathrm{C}$ and $-10^{\circ} \mathrm{C}$ assured the highest cell viability. The survival of yeast strains in the presence of multicomponent cryoprotective agents containing skimmed milk, trehalose and sodium glutamate in three combinations (MT, MG, MTG) was significantly higher than in the presence of those agents used alone. The best agent for Y. lipolytica, C. kefyr and C. sphaerica appeared to be MT, while for C. famata - MG. Cell viability of yeast strains directly after freeze-drying was in the range of 74-80\% and was relatively stable during one-year storage except $C$. famata. Initial yeast growth patterns were very well preserved in most of the preparations during 6 months of storage.

\section{INTRODUCTION}

Yeasts occur as uncontrolled microflora in all maturating cheese varieties. Their number and species composition differ among individual cheeses. Numerous studies prove that the application of selected yeast strains in cheese production leads to many advantages like: ripening process acceleration, quality standardisation or taste and flavour enrichment [Viljoen \& Greyling, 1995; Wyder et al., 1999; Bockelman, 2002; Ferreira \&Viljoen, 2003; De Witt et al., 2005; Szoltysik et al., 2007; De Freitas et al., 2009]. The most promising results were obtained with cultures belonging to the following species: Yarrowia lipolytica, Debaryomyces hansenii (perfect form of Candida famata), Saccharomyces cerevisiae, Kluyveromyces lactis (perfect form of $C$. sphaerica), K. marxianus (perfect form of $C$. kefyr), and Geotrichum candidum [Wyder et al., 1999; Suzzi et al., 2001; Masoud \& Jakobsen, 2005; Boutrou et al., 2006; Kagkli et al., 2006].

In our previous studies four yeast strains were selected as adjunct cultures to lactic acid bacteria for cheese making [Juszczyk et al., 2003, 2005; Zarowska et al., 2004; Polomska et al., 2007]. Those strains were chosen from a numerous group of isolates from Polish blue-veined cheese Rokpol due to high hydrolytic properties of milk proteins and fat (Y. lipolytica, C. kefyr and C. sphaerica) or deacidifying abilities and killer activity against other yeasts occurring in cheese $(C$. famata, $C$. kefyr and $C$. sphaerica). All strains were successfully used as na-

\footnotetext{
* Corresponding author: Tel.: +48 713207 791; Fax: +48 713207 794;

E-mail: x.polomska@wp.pl (X. Połomska)
}

tive cultures in laboratory scale cheese production [Czajgucka et al., 2006] and half-industrial scale production of Dutch-type cheese [unpublished results].

Modern industry requires the application of preserved microbial cultures for the facilitation of production process. Freeze-drying is widely used to this end, but the preservation process can cause cells damage leading to their death or technological quality deterioration. Those consequences can be minimised by optimising freeze-drying conditions [Berny \& Hennebert, 1991], using cryoprotective agents [Berny \& Hennebert, 1991; Lodato et al., 1999; Cerrutti et al,. 2000; Abadias et al., 2001], etc. Nevertheless, preservation conditions should be selected for individual strains.

So far, studies have mainly been focused on cell viability rather overlooking other technological characteristics such as growth or enzymatic activities. The available data concern primarily $S$. cerevisiae yeast species applied in alcohol fermentation or baking [Lodato et al., 1999; Beney et al., 2000; Cerrutti et al., 2000; Miyamoto-Shinohara et al., 2006; Kandylis et al., 2010]. Bretanomyces bruxellensis collection strain as well as C. sake, Cryptococcus laurenti, Rhodotorula glutinis and Pichia anomala used as fruit and cereal biocontrol agents were tested as well [Abadias et al., 2001; Melin et al., 2007; Li et $a l, .2008]$. However, there is a lack of information concerning freeze-drying of cheese-making yeast species. Thus, the objective of the present study was to assess the influence of freeze-drying process parameters and cryoprotective agents on viability as well as growth activity of four selected yeast strains directly after freeze-drying and during one year storage. 


\section{MATERIALS AND METHODS}

\section{Yeast strains}

Four yeast strains originating from yeast culture collection of Biotechnology and Food Microbiology Department, Wroclaw University of Environmental and Life Sciences, were used in the study: Yarrowia lipolytica PII6a, Candida famata MI1a, C. sphaerica FII7a, and C. kefyr PII1b. The strains were previously isolated from blue veined cheese Rokpol [Wojtatowicz et al., 2001]. Yeast biomass was maintained at $4^{\circ} \mathrm{C}$ on YM agar slants (3 g/L yeast extract, BD, Franklin Lakes, NJ, USA; $3 \mathrm{~g} / \mathrm{L}$ malt extract, BD; $5 \mathrm{~g} / \mathrm{L}$ bactopeptone, BD; $20 \mathrm{~g} / \mathrm{L}$ glucose; $15 \mathrm{~g} / \mathrm{L}$ agar).

\section{Biomass production}

Yeast strains were grown in MM medium $(70 \mathrm{~g} / \mathrm{L}$ malt extract, BD, Franklin Lakes, NJ, USA; 3 g/L yeast extract, BD; $\left.1 \mathrm{~g} / \mathrm{L}\left(\mathrm{NH}_{4}\right)_{2} \mathrm{SO}_{4} ; 0.5 \mathrm{~g} / \mathrm{L} \mathrm{KH}_{2} \mathrm{PO}_{4} ; 0.25 \mathrm{~g} / \mathrm{L} \mathrm{MgSO}_{4} \times 7 \mathrm{H}_{2} \mathrm{O}\right)$ selected previously due to high biomass yield [Polomska et al., 2007b]. Cultures were run in conical flasks with $250 \mathrm{~mL}$ capacity in $25 \mathrm{~mL}$ of medium on a rotary shaker (Gyrotory Shaker G10, New Brunswick Co., Edison, NJ, USA) at $28^{\circ} \mathrm{C}$ till they reached an early stationary phase. Biomass was separated by aseptic centrifugation (Sigma K-3, Sigma, Osterode am Harz, Germany), washed twice and resuspended in sterile distilled water to yield heavy cell suspension.

\section{Samples preparation for freeze-drying}

Yeast suspensions of the final concentration approx. $1 \times 10^{9}$ cells $/ \mathrm{mL}$ were prepared in a $10 \%(\mathrm{w} / \mathrm{v})$ solution of cryoprotective substance: skimmed milk powder (M), trehalose $(\mathrm{T})$ or sodium glutamate $(\mathrm{G})$. Protective agents were used alone or in combinations of two (MT, MG) or three components (MTG). Regenerated skimmed milk (M) was sterilised by autoclaving at $117^{\circ} \mathrm{C}$ for $15 \mathrm{~min}$, trehalose $(\mathrm{T})$ and sodium glutamate $(\mathrm{G})$ solutions by filtration using Rotilabo filters of $0.22 \mu \mathrm{m}$ (Roth Industries, Zielona Gora, Poland).

In the experiments with single cryoprotective agent, the cell suspension (approx. $2 \times 10^{9}$ cells $/ \mathrm{mL}$ ) was mixed with $20 \% \mathrm{M}, 20 \% \mathrm{~T}$ or $20 \% \mathrm{G}$ in a proportion of $1: 1$. For bicomponent mixtures of cryoprotectants, the cell suspension (approx. $3 \times 10^{9}$ cells $/ \mathrm{mL}$ ) was mixed with $30 \% \mathrm{M}$ and $30 \% \mathrm{~T}$ or with $30 \% \mathrm{M}$ and $30 \% \mathrm{G}$ in a proportion of $1: 1: 1$. In the case of tricomponent cryoprotectants, the cell suspension (approx. $3 \times 10^{9}$ cells $/ \mathrm{mL}$ ) was mixed with $30 \% \mathrm{M}$ and a solution containing $30 \% \mathrm{~T}$ and $30 \% \mathrm{G}$ in a proportion of 1:1:1. The aliquots of $1 \mathrm{~mL}$ of the cell suspension in the protective mixture were pipetted into sterile vials (10 $\mathrm{mL}$ capacity) and stopped loosely with rubber corks.

\section{Freeze-drying conditions}

In the study three different protocols of the freeze-drying process were applied. In all cases the cell preparations were frozen on the shelf of Alfa 2-4 freeze-dryer (Christ, Osterode am Harz, Germany) at $-38^{\circ} \mathrm{C}$ for $3 \mathrm{~h}$ and then dried for $21 \mathrm{~h}$. Drying parameters were as follows: (I) $-38^{\circ} \mathrm{C}, 0.16$ mbar, $21 \mathrm{~h}$; (II) $-38^{\circ} \mathrm{C}, 0.16$ mbar, $1 \mathrm{~h} ;-10^{\circ} \mathrm{C}, 1.03$ mbar, $20 \mathrm{~h}$; and (III) $-38^{\circ} \mathrm{C}, 0.16$ mbar, $1.5 \mathrm{~h} ;-20^{\circ} \mathrm{C}, 1.03$ mbar, $15 \mathrm{~h}$; $-10^{\circ} \mathrm{C}, 1.25 \mathrm{mbar}, 4.5 \mathrm{~h}$. After completion of the freeze-drying process the vials were closed under vacuum and stored at $4^{\circ} \mathrm{C}$ for 12 months.

\section{Cell viability determination}

The viable cells were counted in three parallel vials, immediately after freeze-drying and then after 6 and 12 months of storage. Dried samples were rehydrated with $1 \mathrm{~mL}$ of sterile distilled water for $5 \mathrm{~min}$ at room temperature and suitable dilutions were plated onto YM agar in five replicates. Plates were incubated at $28^{\circ} \mathrm{C}$ for $72 \mathrm{~h}$ and the number of colony-forming units $(\mathrm{CFU} / \mathrm{mL})$ was counted. Results were expressed as a percentage of viable cells compared to the initial cell number in the suspension before freeze-drying.

\section{Assessment of yeast growth activity}

Growth activity of freeze-dried yeast strains (after 0, 6, 12 months of storage) as well as of unpreserved yeasts was assessed in cultures performed in Automated Microbiology Workstation Bioscreen C (Labsystems Oy, Helsinki, Finland). The device facilitates performing 200 separated shaken microcultures and monitoring optical density during the growth of microorganisms. Yeasts were grown in RW-YE medium prepared from rennet whey and yeast extract $(3 \mathrm{~g} / \mathrm{L}, \mathrm{BD})$ with or without addition of sodium chloride $(2.5 \%)$.

Freeze-dried yeast preparations were rehydrated with $1 \mathrm{~mL}$ of sterile water. The cell suspension standardised to about $7 \times 10^{6} \mathrm{CFU} / \mathrm{mL}$ was used as the inoculum for microcultures. The suspensions of unpreserved yeast strains of the same cell density were used as a control. Cuvettes on honeycomb plates were filled with $300 \mu \mathrm{L}$ of medium and $50 \mu \mathrm{L}$ of cell suspension. Each variant was prepared in five replicates. Cultures were shaken continuously at $25^{\circ} \mathrm{C}$ for $72 \mathrm{~h}$. Bio-Link $5.30 \mathrm{soft}-$ ware (Labsystems Oy, Helsinki, Finland) was incorporated for plotting growth curves from OD values obtained with a wide band filter $(420 \div 580 \mathrm{~nm})$ and calculation of AREA coefficient (area under the growth curve between OD values at $0 \mathrm{~h}$ and $72 \mathrm{~h}$ of cultivation). The results were expressed as a percentage of AREA coefficient of unpreserved yeasts.

\section{Statistical analysis}

The results of cell viability and growth activity expressed as AREA coefficient were tested statistically. The analysis of variance (ANOVA) was employed to evaluate the differences between preparations of the same strain as well as between different strains using Statistica 6.0 software (StatSoft Inc., Tulsa, USA). Kalmogorof-Smirnof test was applied to compare means and to assess the significance of their differences $(\mathrm{p}<0.05)$.

\section{RESULTS AND DISCUSSION}

Conducted investigations are the first studies concerning the preparation of freeze-dried yeast adjunct cultures designed for cheese-making. Starter cultures for that industry should have high and stabile number of viable cells during the longest possible validity time as well as unchanged technological features, like growth and hydrolytic activity. Many factors influence the maintenance of those characteristics. 
One of them is the manner of running the lyophilisation process. In thematic literature many sublimation drying methods are applied: one-step drying at the same temperature as freezing [Miyamoto-Shinohara et al., 2000; Abadias et al., 2001; Blanquet et al., 2005; Li et al., 2008], drying with uniform increase of temperature [Berny \& Hennebert, 1991] or multi-step drying [Melin et al., 2007, 2011]. However, we have not found any report comparing different processes on the example of one organism.

Our results prove that the conditions of sublimation drying have a crucial effect on cell survival, which can be observed on the example of $C$. kefyr PII1b strain (Figure 1). The best viability was noted in the case of Process III with three steps of drying in temperature sequence: $-38^{\circ} \mathrm{C},-20^{\circ} \mathrm{C}$ (main drying) and $-10^{\circ} \mathrm{C}$. The application of one-step drying at the temperature of freezing (Process I) and two-step drying with main drying at $-10^{\circ} \mathrm{C}$ (Process II) gave significantly worse viability results. Similar dependencies were obtained for three other tested strains (data not shown), thus the conditions of Process III were applied in further experiments.

Our observations showing that raising temperature during lyophilisation increases the cell survival corresponds with literature data. The viability of $S$. cerevisiae freeze-dried with uniformly increasing temperature during drying was several dozen times higher than in the one-step drying process [Berny \& Hennebert, 1991; Cerrutti et al., 2000; Miyamoto-Shinohara et al., 2000].

A detrimental influence of preservation conditions may be effectively mitigated by the addition of proper cryoprotective agent [Hubalek, 2003]. In this investigation, skimmed milk $(\mathrm{M})$, trehalose $(\mathrm{T})$, sodium glutamate $(\mathrm{G})$ and their mixtures (MT, MG and MTG) were employed. Each of those agents reveals different activity. Milk is mainly used for uniform porous structure assurance of freeze-dried preparation, enabling both easy sample desiccation and subsequent rehydratation [Hubalek, 2003]. Freeze-dried samples with that agent showed very good preparation structure during one-year storage. Trehalose, due to glassy state formation and structural water particles replacement in hydrogen bonds created with lipids and proteins, causes membranes stabilisation [Crowe et al., 1996; Crowe, 2000; Mazzobre et al., 1997]. In turn, sodium glutamate because of its antioxidative action prevents oxidation reactions of triacyl-glycerols as well as free radicals formation, which can lead to irreversible cell damage [Abadias et al., 2001].

Figure 2 shows the effect of single cryoprotective agents (M, T and G) on viability of all tested yeast strains after freeze-drying and also after 6 and 12 months of storage at $4^{\circ} \mathrm{C}$. The viability depended on yeast strain and cryoprotective agent used. Directly after the freeze-drying process it was quite high and ranged between $20 \%$ and $60 \%$. The highest survival percentage of $Y$. lipolytica PII6a strain was achieved in milk (M, 51\%), while that of $C$. famata MIla in trehalose (T, 60\%). The best preservation results of $C$. kefyr PII1b and $C$. sphaerica FII7a were obtained with sodium glutamate ( $\mathrm{G}, 58 \%$ and $54 \%$, respectively). However, a significant decrease of yeast viability during storage occurred in most of the preparations, especially in those obtained with sodium glutamate, where cells survival decreased even to less

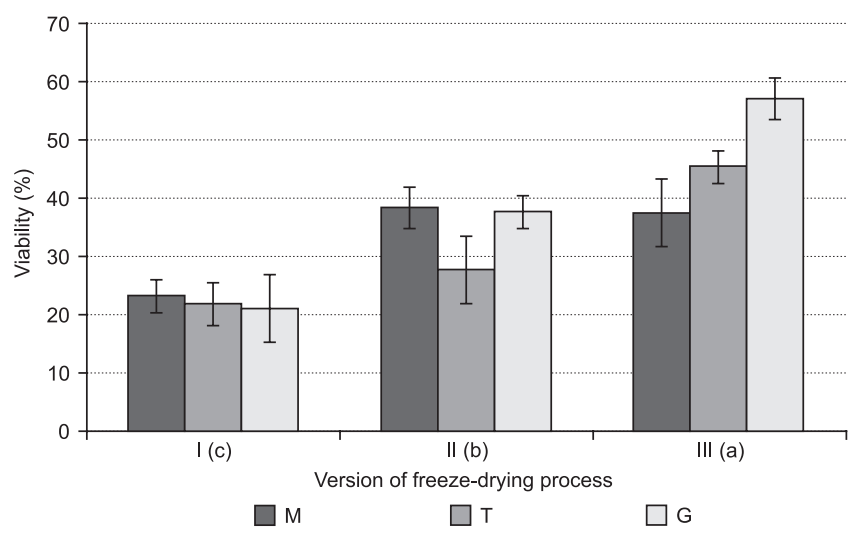

FIGURE 1. Influence of freeze-drying process on cell viability of $C$. kefyr PIIlb strain. In all cases cells were frozen at $-38^{\circ} \mathrm{C}$ for $3 \mathrm{~h}$ then dried as follows: (I) $-38^{\circ} \mathrm{C}, 21 \mathrm{~h}$; (II) $-38^{\circ} \mathrm{C}, 1 \mathrm{~h} ;-10^{\circ} \mathrm{C}, 20 \mathrm{~h}$; (III) $-38^{\circ} \mathrm{C}, 1.5 \mathrm{~h} ;-20^{\circ} \mathrm{C}$, $15 \mathrm{~h} ;-10^{\circ} \mathrm{C}, 4.5 \mathrm{~h}$. Yeast cells were suspended in single cryoprotective agents: skimmed milk $(\mathrm{M})$, trehalose $(\mathrm{T})$ and sodium glutamate $(\mathrm{G})$. Presented data are mean values from the analyses of three vials, each in five replicates \pm standard deviation. Significantly different versions of freeze-drying process are indicated with different letters in brackets $(\mathrm{p}<0.05)$.

than $0.1 \%$ after 6 months of storage, which was correlated with incomplete drying of those samples. The least decrease of cell viability was observed in M preparations; after one year of storage over $10 \%$ of living cells were still present in the case of all tested strains except for Y. lipolytica PII6a.

Cell viability was significantly improved by the application of multicomponent protection media (MT, MG, and MTG) and remained relatively stable in most of preparations during one-year storage (Figure 3). Strain-dependent sensitivity to freeze-drying was less visible than with single cryoprotective agents. The application of MT as a cryoprotectant enabled very high survival of $Y$. lipolytica PII6a, C. kefyr PII1b and $C$. sphaerica FII7a strains (74-80\%) directly after freeze-drying. That mixture also appeared to be the best lyoprotectant of those strains during storage; viability decreased only to $55-62 \%$ after one year. A similar viability level was maintained in MG preparations of Y. lipolytica PII6a and C. kefyr PII1b. On the other hand, in all preparations of $C$. famata MI1a higher decrease of viable cells was observed during freeze-drying and storage. The best cryoprotectant for that strain directly after preservation and 12 months of storage appeared to be $\mathrm{MG}$.

Our results are in agreement with findings of other authors. Berny \& Hennebert [1991] after preservation of S. cerevisiae and Bretanomyces bruxellensis yeasts observed a considerable increase of cell survival in mixtures of cryoprotective agents, both two- and three-compound, compared with those compounds used alone. Similar observations were made by Abadias et al. [2001] during freeze-drying of $C$. sake in the presence of milk, trehalose and their mixture. Blanquet et al. [2005] confirmed such relations in the case of genetically-modified yeasts, which are usually more sensitive. The use of milk together with trehalose allowed the significant viability increase of those yeasts.

Our results indicate also that appropriately assorted cryoprotective agents can prevent a significant decrease of viable cell number during one-year storage of preparations, allowing the extension of validity period of commercial starter cultures. 

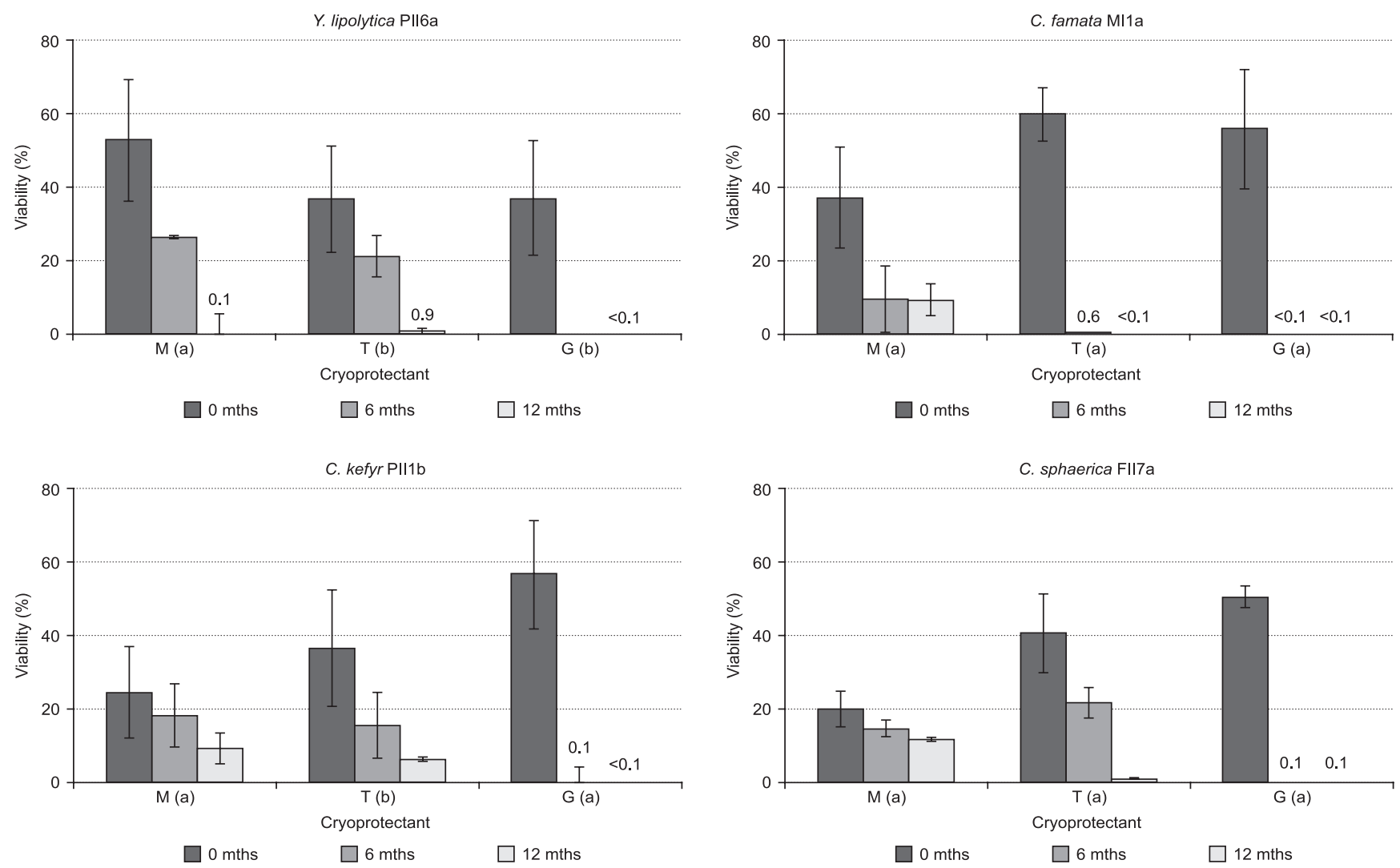

FIGURE 2. Effect of single cryoprotective agents on viability of yeast cells after freeze-drying ( 0 months) and successive storage (6 and 12 months). Cryoprotective agents: skimmed milk $(\mathrm{M})$, trehalose $(\mathrm{T})$, sodium glutamate $(\mathrm{G})$. Presented results are mean values from the analyses of three vials, each in five replicates \pm standard deviation.
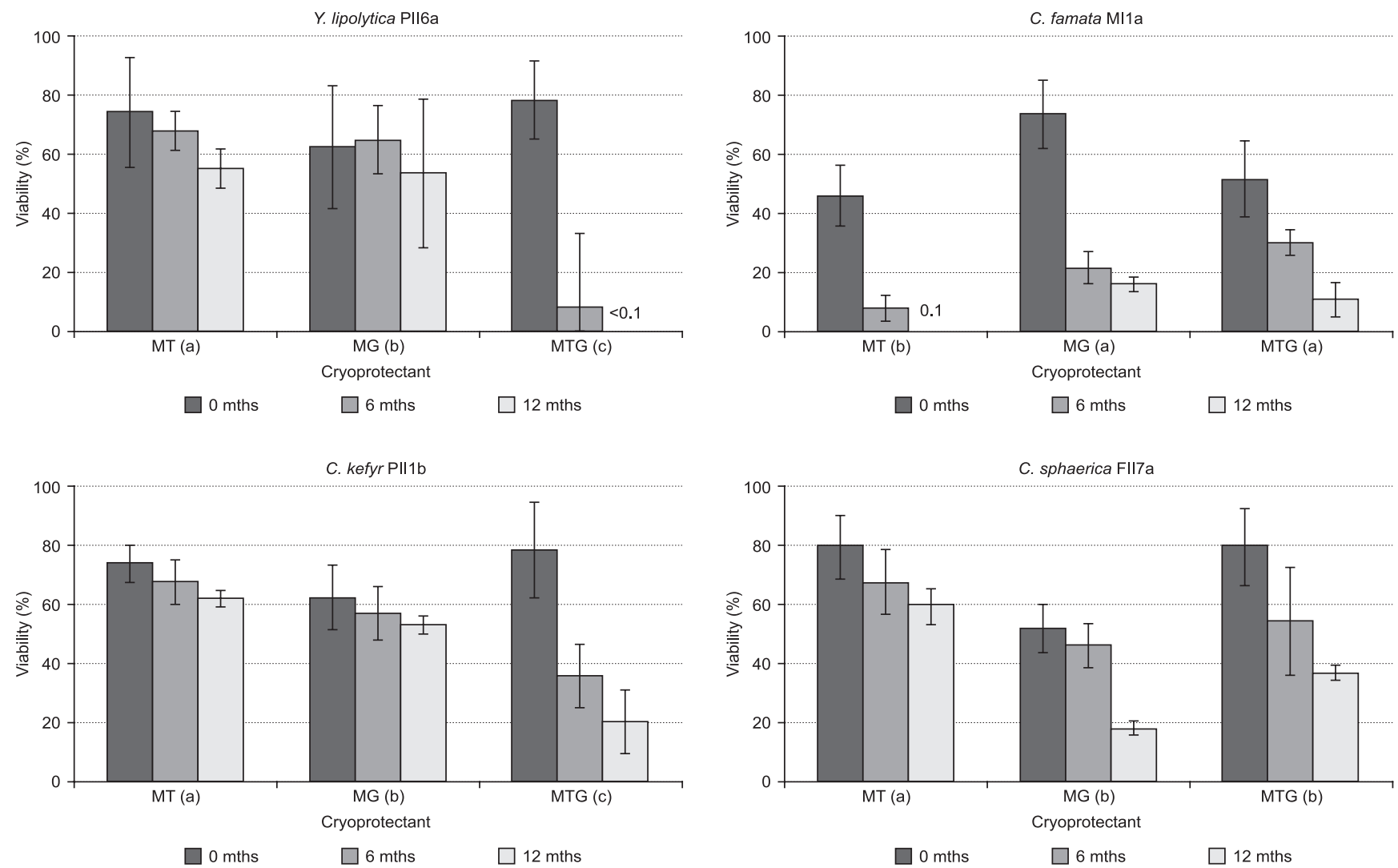

FIGURE 3. Effect of multicomponent cryoprotective agents on viability of yeast cells after freeze-drying ( 0 months) and successive storage (6 and 12 months). Cryoprotective agents: skimmed milk + trehalose (MT), skimmed milk + sodium glutamate (MG), skimmed milk + trehalose + sodium glutamate (MTG). Presented results are mean values from the analyses of three vials, each in five replicates \pm standard deviation. 

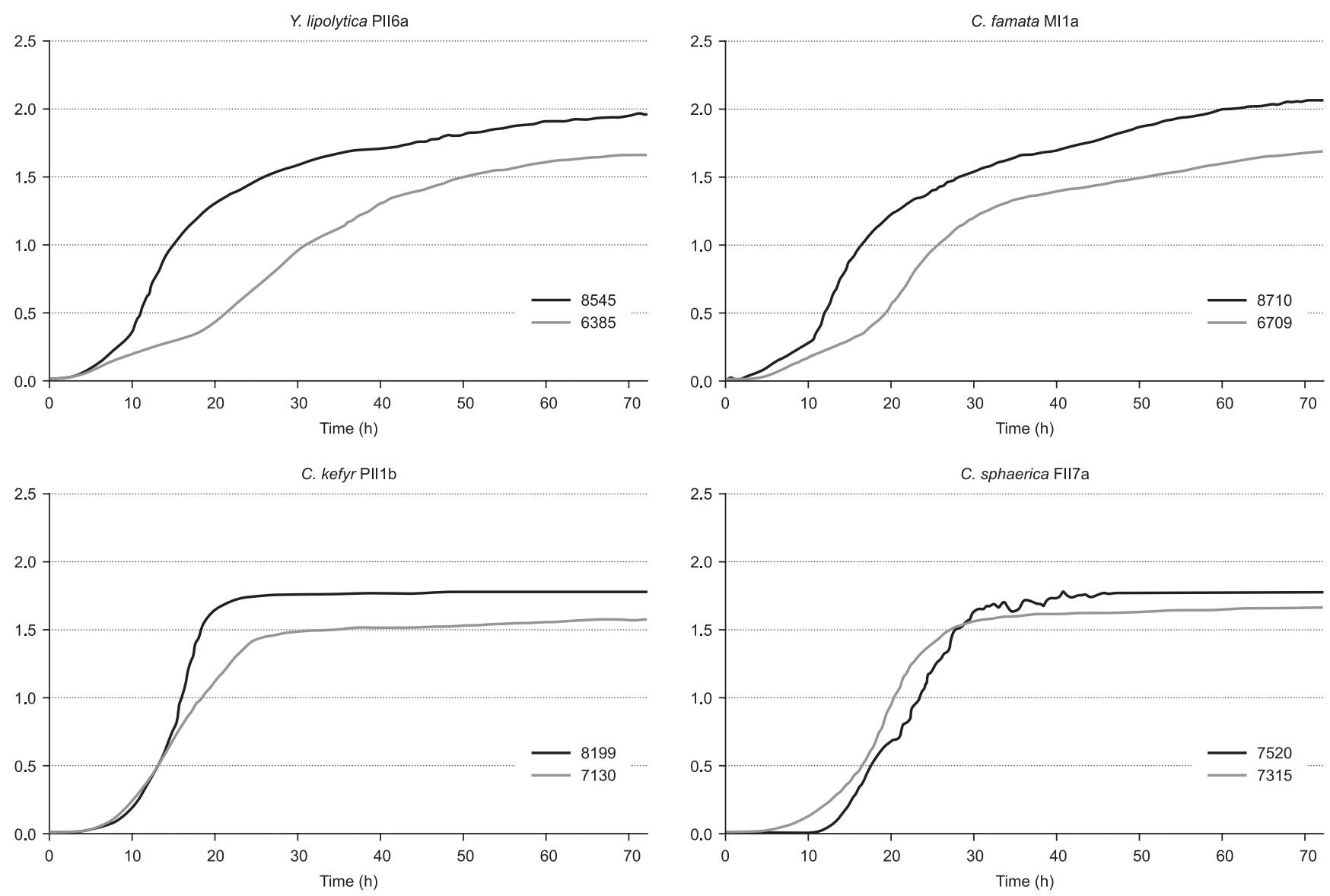

FIGURE 4. Growth curves of unpreserved yeasts in RW-YE medium with different $\mathrm{NaCl}$ concentration: $0 \%$ (一) and 2.5\% (-) and coressponding AREA coefficient calculated by Bio-Link sofware.

Literature data also indicate rather a slow rate of yeast cells dying during long-term storage. Miyamoto-Shinohara et al. [2006] found that the number of living cells in preparations of $S$. cerevisiae, preserved in a suspension of skimmed milk with addition of sodium glutamate, underwent higher reduction during freeze-drying (approx. 90\%) than during long-term storage (only $2.3 \%$ per year).

To investigate changes in growth pattern of the tested strains caused by preservation and storage, freeze-dried yeasts were rehydrated and after standardisation introduced to RW-YE medium differing with salt concentration (0\% and $2.5 \%)$. The study involved only preparations obtained with multicomponent cryoprotectants. Growth curves of the preserved yeasts were compared to those of unpreserved cells (Figure 4). To facilitate comparisons, results were presented as percentage of initial AREA value obtained for unpreserved yeasts. The AREA coefficient enables the detection of even subtle changes in each growth phase. A fine example can be the growth curves of $C$. sphaerica FII7a and AREA values corresponding to them; despite the slight differences between plots of growth, AREA values differed remarkably (7315 and 7520, respectively).

In the present study, the stability of yeasts growth activity after freeze-drying and storage depended on individual sensitivity of particular strains (Table 1). However, the influence of a cryoprotective agent on the maintenance of initial growth characteristics was not as important as in the case of cell viability. Most of $Y$. lipolytica PII6a preparations revealed relatively well preserved growth activity directly after freeze-drying as well as after storage. Only in MTG preparation was a greater decrease of growth activity observed between the $6^{\text {th }}$ and the $12^{\text {th }}$ month of storage. It is worth mentioning that in two $Y$. lipolytica yeast preparations an increase was observed in AREA coefficient directly after freeze-drying. This may indicate better preservation and selection of cells with a higher growth activity during processing. In the case of $C$. famata MIla strain, the freeze-drying process caused a decrease of AREA value in both tested growth media and a further progressive decrease of that coefficient along with storage time. No statistically significant differences were observed between individual cryoprotective agents. Directly after lyophilisation C. kefyr PIIlb and C. sphaerica FII7a yeast strains in all freeze-dried preparations showed growth activity similar to that before the preservation process; AREAs were in the range of 94-103\% of the initial value in the two tested growth media. Along with storage time growth characteristics of freeze-dried yeast was only slightly deteriorating. Preparations of $C$. sphaerica FII7a lyophilised in the presence of MT and MTG as cryoprotectants showed a very high growth activity (about $100 \%$ of the initial AREA value in both tested growth media), which was stable during 12 months of storage.

The decrease of AREA coefficient during storage of freeze-dried preparations was connected with the extension of lag- 
TABLE 1. Percentage of initial AREA coefficient of freeze-dried yeast strains in growth medium with different NaCl concentration ${ }^{1}$.

\begin{tabular}{|c|c|c|c|c|c|c|c|}
\hline \multirow[b]{2}{*}{ Yeast strain } & \multirow[b]{2}{*}{ Storage (mths) } & \multicolumn{3}{|c|}{$0 \% \mathrm{NaCl}$} & \multicolumn{3}{|c|}{$2.5 \% \mathrm{NaCl}$} \\
\hline & & 0 & 6 & 12 & 0 & 6 & 12 \\
\hline \multirow{3}{*}{ Y. lipolytica $\mathrm{PII} 6 \mathrm{a}^{\mathrm{I}}$} & $\mathrm{MT}^{\mathrm{a}}$ & 118.0 & 96.9 & 78.4 & 118.0 & 111.5 & 98.6 \\
\hline & $\mathrm{MG}^{\mathrm{a}}$ & 100.7 & 91.7 & 75.4 & 113.2 & 104.8 & 93.5 \\
\hline & $\mathrm{MTG}^{\mathrm{b}}$ & 98.6 & 85.2 & 37.7 & 110.0 & 86.1 & 32.8 \\
\hline \multirow{3}{*}{ C. famata MI1 ${ }^{\mathrm{II}}$} & $\mathrm{MT}^{\mathrm{a}}$ & 88.2 & 63.5 & 44.3 & 80.9 & 75.1 & 64.3 \\
\hline & $\mathrm{MG}^{\mathrm{a}}$ & 90.2 & 66.6 & 52.9 & 81.2 & 79.6 & 71.8 \\
\hline & $\mathrm{MTG}^{\mathrm{a}}$ & 88.0 & 59.8 & 50,2 & 74.5 & 77.7 & 65.1 \\
\hline \multirow{3}{*}{ C. kefyr PII $1 \mathrm{~b}^{\mathrm{I}}$} & $\mathrm{MT}^{\mathrm{a}}$ & 95.3 & 82.4 & 76.8 & 100.5 & 84.2 & 71.1 \\
\hline & $\mathrm{MG}^{\mathrm{a}}$ & 94.4 & 82.9 & 77.9 & 99.6 & 93.3 & 64.4 \\
\hline & $\mathrm{MTG}^{\mathrm{a}}$ & 95.4 & 82.8 & 77.6 & 101.0 & 97.6 & 66.7 \\
\hline \multirow{3}{*}{ 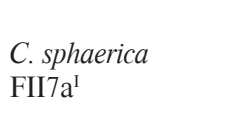 } & $\mathrm{MT}^{\mathrm{a}}$ & 97.8 & 98.3 & 94.4 & 101.1 & 95.1 & 97.5 \\
\hline & $\mathrm{MG}^{\mathrm{b}}$ & 99.5 & 96.8 & 68.2 & 103.4 & 96.0 & 78.9 \\
\hline & $\mathrm{MTG}^{\mathrm{a}}$ & 99.6 & 96.6 & 88.9 & 99.6 & 99.9 & 96.7 \\
\hline
\end{tabular}

${ }^{1}$ statistical significance of differences $(\mathrm{p}<0.05)$ between cryoprotective agents for each strain is marked by different letters and between yeast strains by different Roman numbers.

-phase, specific growth rate reduction or rarely with lowering of the maximal OD value (data not shown). The decrease of yeast cells growth activity during storage in freeze-dried form was also observed by Kandylis et al. [2010], who used lyophilised $S$. cerevisiae yeasts for grape must fermentation. Researchers have noted a longer fermentation time during the first two batches, which became equalised after successive batches. Blanquet et al. [2005] observed the elongation of the lag-phase of lyophilised S. cerevisiae yeasts in YPG medium, when comparing to unpreserved yeasts, which suggested that cell repair processes of damaged structures and macromolecules proceeded just in that growth phase.

In the present study, the increase of AREA coefficient, especially directly after the freeze-drying process was also observed. It was usually caused by the increase of maximal OD during cultivation (data not shown). Authors did not find similar observations in other works. The increase of salt tolerance of the tested yeast strains was observed as well. Such an effect was probably correlated with dying out of more sensitive cells in freeze-dried preparations.

Among four tested yeast strains, C. famata MI1a differed significantly in both viability and maintenance of initial growth activity, despite the fact that this species belongs to halotolerant organisms and should better tolerate relatively slow cooling, generating the increase of environmental osmotic pressure. A similar observation was made by Cerrutti et al. [2000], who noticed increased sensitivity to freeze-drying of other osmotolerant yeasts - Zygosaccharomyces rouxii. The explanation of such a phenomenon was suggested by Khroustalyova et al. [2001]. Those authors claimed that in contrast to non-halophilic yeast species Debaryomyces hansenii perfect form of $C$. famata, is more sensitive to dehydration when harvested at stationary than at logarithmic phase. Our unpublished results confirm that suggestion. We obtained enhanced resistance to freeze-drying of that strain when biomass was collected at the stationary phase of culture performed in the presence of a high concentration of $\mathrm{NaCl}$, which forces cells to produce intracellular protectants.

The utilisation of freeze-dried yeast cultures obtained in this study in cheese production will be the subject of the next publication.

\section{CONCLUSIONS}

Our studies were focused on freeze-drying preservation of yeast strains (Yarrowia lipolytica PII6a, Candida famata MI1a, C. kefyr PII1b, C. sphaerica FII7a), potential starters for cheese production. We tested the influence of freeze-drying process parameters and cryoprotective agents on viability as well as growth activity of selected yeast strains directly after freeze-drying and during one year storage.

From three analysed protocols the process with three-step drying at temperatures of $-38^{\circ} \mathrm{C},-20^{\circ} \mathrm{C}$ and $-10^{\circ} \mathrm{C}$ resulted in the highest cell viability. Two (MT, MG) and three-component (MTG) mixtures of cryoprotective agents assured considerably higher cell viability of all tested yeast strains during freeze-drying and 12 months of storage when compared to single cryoprotectants (skimmed milk - M, trehalose - $\mathrm{T}$ or sodium glutamate - G). The best agent for Y. lipolytica, C. kefyr and $C$. sphaerica appeared to be MT, while for $C$. famata - MG. The initial growth pattern was well preserved in most lyophilised yeast preparations during 6 months of storage. The effect of a cryoprotective agent on preservation of this characteristic was not so significant as in the case of cell viability.

\section{ACKNOWLEDGEMENTS}

This work was financially supported under a grant from the Polish State Committee for Scientific Research (KBN) 2PO6T 05028. 


\section{REFERENCES}

1. Abadias M., Benabarre A., Teixido N., Usall J.,Vinas I., Effect of freeze drying and protectants on viability of the biocontrol yeast Candida sake. Int. J. Food Microbiol., 2001, 65, 173-182.

2. Beney L., Martinez de Maranon I., Marechal P.A., Gervais, P., Influence of thermal and osmotic stresses on the viability of the yeast Saccharomyces cerevisiae. Int. J. Food Microbiol., 2000, 55, 275-279.

3. Berny J.F., Hennebert, G.L., Viability and stability of yeast cells and filamentous fungus spores during freeze-drying: effects of protectants and cooling rates. Mycologia, 1991, 83, 805-815.

4. Blanquet S., Garrait G., Beyssac E., Perrier C., Denis S., Hebrard G., Alric M., Effects of cryoprotectants on viability and activity of freeze dried recombinant yeasts as novel drug delivery systems assessed by an artificial digestive system. Eur. J. Pharm. Biopharm., 2005, 61, 32-39.

5. Bockelmann W., Development of defined surface starter cultures for the ripening of smear cheeses. Int. Dairy J., 2002, 12, 123-131.

6. Boutrou R., Kerriou L., Gassi J-Y., Contribution of Geotrichum candidum to the proteolysis of soft cheese. Int. Dairy J., 2006, 16, 775-783.

7. Cerrutti P., Segovia de Huergo M., Galvagno M., Schebor C., del Pilar Buera, M., Commercial baker's yeast stability as affected by intracellular content of trehalose, dehydration procedure and the physical properties of external matrices. Appl. Microbiol. Biotechnol., 2000, 54, 575-580.

8. Crowe J.H., Hoekstra F.A., Nguyen K.H.N., Crowe L.M., Is vitrification involved in depression of the phase transition temperature in dry phospholipids? Biochim. Biophys. Acta, 1996, 1280, 187-196.

9. Crowe L.M., Lessons from nature: preservation of membranes by trehalose. Comp. Biochem. Physiol., 2000, 126, S34.

10. Czajgucka A., Chrzanowska J., Juszczyk P., Szołtysik M., Połomska X., Wojtatowicz M., Yeast growth in model cheese and their effect on protein and fat degradation. Acta Sci. Pol., Biotechnol., 2006, 5, 95-103.

11. De Freitas I., Pinon N., Maubois J-L., Lortal SA., Thierry A., The addition of a cocktail if yeast species to Cantalet cheese changes bacterial survival and enhances aroma compounds formation. Int. J. Food Microbiol., 2009, 129, 37-42.

12. De Wit M., Osthoff G., Viljoen B.C., Hugo A., A comparative study of lipolysis and proteolysis in Cheddar cheese and yeast-inoculated Cheddar cheeses during ripening. Enz. Microbial Technol., 2005, 37, 606-616.

13. Ferreira A.D., Viljoen B.C., Yeasts as adjunct starters in matured Cheddar cheese. Int. J. Food Microbiol., 2003, 86, 131-140.

14. Hubalek Z., Protectants used in the cryopreservation of microorganisms. Cryobiology, 2003, 46, 205-229.

15. Juszczyk P., Wojtatowicz M., Żarowska B., Chrzanowska J., Malicki A., Diversity of physiological and biochemical properties within yeast species occurring in Rokpol cheese. Pol. J. Food Nutr. Sci., 2005, 4, 37-41.

16. Juszczyk P., Żarowska B., Wojtatowicz M., Chrzanowska J., Heat resistance of yeast strains selected as co-starters for cheese production. Acta Sci. Pol., Biotechnol., 2003, 2, 51-58.

17. Kagkli D.-M., Tache R., Cogan T.M., Hill C., Casaregola S., Bonnarme P., Kluyveromyces lactis and Sacharomyces cerevisiae, two potent deacidifying and volative-sulphur-aroma-producing microorganisms of the cheese ecosystem. Appl. Microbiol. Biotechnol. - proszę sprawdzić., 2006, 73, 434-442.

18. Kandylis P., Manousi M.-E., Bekatorou A., Koutinas A.A., Freeze-dried wheat supported biocatalyst for low temperature wine making. LWT - Food Sci. Technol., 2010, 43, 1485-1493 .

19. Khroustalyova G., Adler L., Rapoport A., Exponential growth phase cells of the osmotolerant yeast Debaryomyces hansenii are extremely resistant to dehydration stress. Proc. Biochem., 2001, 36, 1163-1166.

20. Li B.Q., Zhou Z.W., Tian S.P., Combined effects of endoand exogenous trehalose on stress tolerance and biocontrol efficacy of two antagonistic yeasts. Biol. Control., 2008, 46, 187-193.

21. Lodato P., Segovia de Huergo M., Buera M.P., Viability and thermal stability of a strain of Saccharomyces cerevisiae freeze-dried in different sugar and polymer matrices. Appl. Microbiol. Biotechnol., 1999, 52, 215-220.

22. Masoud W., Jakobsen M., The combined effects of $\mathrm{pH}, \mathrm{NaCl}$ and temperature on growth of cheese ripening cultures of $D e-$ baryomyces hansenii and coryneform bacteria. Int. Dairy J., 2005, $15,69-77$.

23. Mazzobre M.F., del Pilar Buera M., Chirife G., Protective role of trehalose on thermal stability of lactase in relation to its glass and crystal forming properties and effect of delaying crystallization. Lebensmitt.- Wiss. Technol., 1997, 30, 324-329.

24. Melin P., Hakansson S., Schnurer J., Optimisation and comparison of liquid and dry formulations of the biocontrol yeast Pichia anomala J121. Appl. Microbiol. Biotechnol., 2007, 73, 1008-1016.

25. Melin P., Schnurer J., Hakansson S., Formulation and stabilisation of the biocontrol yeast Pichia anomala. Ant. van Leeuwen., 2011, 99, 107-112.

26. Miyamoto-Shinohara Y., Imaizumi T., Sukenobe J., Murakami Y., Kawamura S., Komatsu Y., Survival rate of microbes after freeze-drying and long-term storage. Cryobiology, 2000, 41, 251-255.

27. Miyamoto-Shinohara Y., Sukenobe J., Imaizumi T., Nakahara T., Survival curves of microbial species stored by freeze-drying. Cryobiology, 2006, 52, 27-32.

28. Polomska X., Juszczyk P., Cadez N., Raspor P., Robak M., Wojtatowicz M., Comparison of physiological and PCR-RFLP rDNA identification of yeast species commonly found in cheese. Pol. J. Food Nutr. Sci., 2007a, 57, 221-226.

29. Polomska X., Wojtatowicz M., Zarowska B., Szoltysik M., Chrzanowska J., Screening of growth media for freeze-dried yeast starter cultures for cheese making. Acta Sci. Pol., Biotechnol., 2007b, 6, 3-14.

30. Suzzi G., Lanorte M.T., Galgano F., Andrighetto C., Lombardi A., Lanciotti R., Guerzoni M.E., Proteolytic, lipolytic and molecular characterization of Yarrowia lipolytica isolated from cheese. Int. J. Food Microbiol., 2001, 69, 69-77.

31. Szołtysik M., Zelazko M., Dabrowska A., Połomska X., Wojtatowicz M., Comparison of aroma compounds profiles of commercial cheeses and cheese produced with yeast Yarrowia lipolytica. Acta Sci. Pol., Biotechnol., 2007, 6, 33-43.

32. Viljoen B.C., Greyling T., Yeast associated with Cheddar and Gouda making. Int. J. Food Microbiol., 1995, 28, 79-88. 
33. Wojtatowicz M., Chrzanowska J., Juszczyk P., Skiba A., Gdula A., Identification and biochemical characteristics of yeast microflora of Rokpol cheese. Int. J. Food Microbiol., 2001, 69, 135-140.

34. Wyder M.T., Bachmann H.P., Puhan Z., Role of selected yeasts in cheese ripening: an evaluation in foil wrapped Raclette cheese. Lebensmitt. Wiss. Technol., 1999, 32, 333-343.
35. Zarowska B., Wojtatowicz M., Połomska X., Juszczyk P., Chrzanowska J., Factors effecting killer activity of some yeast species occurring in Rokpol cheese. Folia Microbiol., 2004, 49, 713-717.

Received March 2011. Revision received and accepted September 2011. Published on-line on the $28^{\text {th }}$ of March 2012. 